\title{
Uterine Natural Killer Cell Heterogeneity: Lessons From Mouse Models
}

\author{
Dorothy K. Sojka* \\ Rheumatology Division, Washington University School of Medicine, St. Louis, MO, United States
}

Natural killer (NK) cells are the most abundant lymphocytes at the maternal-fetal interface. Epidemiological data implicate NK cells in human pregnancy outcomes. Discoveries using mouse NK cells have guided subsequent advances in human NK cell biology. However, it remains challenging to identify mouse and human uterine NK (UNK) cell function(s) because of the dynamic changes in the systemic-endocrinological and local uterine structural microenvironments during pregnancy. This review discusses

OPEN ACCESS

Edited by:

Ana Claudia Zenclussen,

University Hospital Magdeburg,

Germany

Reviewed by:

Paola Vacca,

Bambino Gesù Children Hospital

(IRCCS), Italy

Francesco Colucci,

University of Cambridge,

United Kingdom

Gendie Lash,

Guangzhou Women and Children's

Medical Center, China

*Correspondence:

Dorothy K. Sojka

dksojka@wustl.edu

Specialty section:

This article was submitted to

Immunological Tolerance and

Regulation,

a section of the journal

Frontiers in Immunology

Received: 06 December 2019

Accepted: 05 February 2020

Published: 21 February 2020

Citation:

Sojka DK (2020) Uterine Natural Killer Cell Heterogeneity: Lessons From

Mouse Models.

Front. Immunol. 11:290.

doi: 10.3389/fimmu.2020.00290 functional similarities and differences between mouse and human NK cells at the maternal-fetal interface.

Keywords: conventional NK cells, pregnancy, maternal-fetal interface, tissue-resident NK cells, uterine NK cells

\section{INTRODUCTION}

Concinnity, the harmonious arrangement of different parts skillfully fitting together, is a word that describes the orchestrated changes that occur between mother and conceptus during pregnancy. The coordinated modifications are supported by the maternal immune system which accommodates the genetically distinct individual. There is no direct contact between the circulations of the mother and the conceptus; however, conceptus-derived extraembryonic membranes evolve into the chorioallantoic placenta and the chorioamnion, both directly bordering maternal tissues of the uterine cavity. As these maternal-fetal boundaries are established, uterine immune cells provide support. Survival of mammalian species defies the classic laws of transplantation immunology.

Mammalian reproductive success depends on tightly-regulated signal coordination that lead to the optimal vascular perfusion of a placenta that supports the fetus. In humans, abnormal spiral artery development is associated with obstetrical syndromes such as preeclampsia (1), a hypertensive disorder that affects 3-7\% of pregnancies. Epidemiological evidence associates preeclampsia with specific maternal natural killer (NK) cell receptors and their cognate human leukocyte antigen class I (HLA-I) ligands expressed by conceptus cells (2-4). The most abundant maternal leukocytes at the maternal-fetal interface are uterine NK (uNK) cells. Therefore, epidemiological data strongly suggest that uNK cells have crucial roles in remodeling the maternal vessels that support placental development and function over pregnancy.

NK cells express killer Ig-like receptors in human (KIRs) and lectin-like receptors in mouse (Ly49s), which are the primary major histocompatibility complex class I (MHC-I)-specific inhibitory receptors. Pregnant women with a specific KIR haplotype carrying a conceptus with a specific HLA-C genotype have significantly greater risk for preeclampsia (2). Expanded evidence for the negative effects of inhibitory receptors on NK cells interacting with their MHC-I ligands on fetal tissues was obtained from a cohort of African women, who have more genetic diversity in KIR haplotypes and HLA alleles (4). Studies associating specific maternal KIR and conceptus HLA 
alleles with preeclampsia strongly suggest a precise role for NK cell receptors that recognize fetal MHC-I, although further in vivo human studies would be challenging. In mice, specific maternal-fetal MHC-I haplotype combinations display differences in decidual vessels, placental sizes, and fetal weights $(5,6)$. Thus, studies of murine NK cells can be used to guide future translational investigations of human pregnancy complications despite species-specific differences between the pregnancies $(7,8)$.

\section{MATERNAL-FETAL INTERFACE}

Human and mouse pregnancies induce environmental changes in uterus that establish receptivity and implantation (9). The maternal-fetal interface includes maternally-derived decidua basalis and conceptus-derived placenta. In humans, endometrial decidualization occurs each menstrual cycle and is shed if implantation does not take place (10). If implantation occurs the decidual cells proliferate, contact invading extravillous trophoblasts (EVTs) and form the decidua basalis. Unobstructed maternal blood flow into the intervillous space occurs between 10 and 12 weeks, marking the end of the first trimester. In mice, blastocyst implantation triggers decidualization, where uterine stromal cells are transformed into large decidual cells that proliferate to surround the implantation site then become the decidua basalis. In both species, decidualization is accompanied by vascular changes and leukocyte accumulation, largely NK cells $(11,12)$. At gestational day 9.5, the murine labyrinthine placenta accepts maternal blood flow and supplies nutrients to the fetus for the remainder of the pregnancy. At this time the mesometrial aggregate of pregnancy (MLAp) forms in the maternal uterine wall of mice but not human (11). The definitive chorioallantoic placenta develops, accompanied by vascular remodeling of the subjacent uterine arteries. The maternal-fetal interface is well established by first trimester (humans) and mid-pregnancy (mice).

\section{PLACENTAL DEVELOPMENT AND FUNCTION}

A placenta anchors each conceptus to the uterine wall, is the site of nutrient, gas, and waste exchange, and induces an immune environment that nurtures and protects the fetus $(13,14)$. Placental dysfunction results in human pregnancy complications that associate with long-term health consequences for both mother and baby. The fetal origins hypothesis, coined by David J.P. Barker [known as the Developmental Origins of Human Adult Disease (DOHAD)], posits that in utero fetal programming mediated by placental function has life-long effects on the baby's health $(15,16)$. Thus, placenta is pivotal not only to fetal development but also offspring health.

While placental structural anatomy varies, in all species the placenta arises from the trophectoderm of the preimplantation blastocyst (17). This layer is programmed to differentiate into fetal membranes while the inner cell mass of the blastocyst evolves the fetus. The mammalian placenta is categorized based on histological structure of the maternal-fetal interface. There are three placental classifications that includes: epitheliochorial (cow, horse, pig), endotheliochorial (dog, cat), and hemochorial (human, rodent). Hemochorial is the most invasive type, in which fetal trophoblast cells invade deeply into the maternal endometrium and vasculature to establish maternal blood perfusion through the placenta.

\section{Hemochorial Placenta}

Human and mouse hemochorial placentas share many features, but differ in ways that affect immunity. The human placenta is structured as chorionic villous trees that are bathed in maternal blood. A single layer of multinucleated syncytiotrophoblast (SynT) surfaces human placental villous trees and lines the intervillous space perfused by maternal blood. Mononucleated cytotrophoblasts are undifferentiated progenitor cells, subjacent to the SynT, that differentiate and fuse to replenish the SynT. Other cytotrophoblasts differentiate into EVTs, which are located at tips of the anchoring villi and invade the decidua basalis and maternal decidual vessels. During first and into early second trimester, human placental villi are hemodichorial, covered with a continuous bilayer of SynT and cytotrophoblasts. The villous cytotrophoblast layer becomes discontinuous during the second trimester yielding a hemomonochorial structure with only a SynT cell barrier between fetal and maternal blood.

In mouse, the definitive chorioallantoic placenta is labyrinthine with two separate, maze-like vascular systems. Branches of the central arteries traverse the junctional zone then perfuse the fetal labyrinth with maternal blood. The irregularlyshaped junctional zone lies between the decidua basalis and labyrinth. The labyrinth is surfaced by two syncytial layers of trophoblast (SynT I and II) and a mononuclear trophoblast layer adjacent to the maternal blood. The labyrinthine structure comprises the interhemal unit, which continuously thins during gestation. Scanning electron microscopy indicates that midgestational mouse placenta is hemodichorial, with direct maternal blood contact of SynT-I as the cellular trophoblast layer becomes incomplete, exposing areas of SynT-II (18). These differences in cellular composition and placental structure may alter immunity at the maternal-placental interface. Thus, mechanisms that protect fetuses from an activated maternal immune system, and block access of maternally circulating pathogens to the fetus may differ spatiotemporally in human and mouse gestations.

\section{Immunological Interface}

Typically, placental membranes separate the semi-allogenic fetus from the maternal immune system throughout gestation, an arrangement that protects against maternal, immune-mediated elimination of the fetus. Multiple immunological interfaces occur between the placenta and maternal immune system. One such interface is between the trophoblast cells that line the chorionic villi (human) and labyrinth structure (mouse) that bathe in maternal blood (Figure 1-II). In human placentas, the SynT cells exposed to maternal blood do not express MHC-I or MHC-II, and do not elicit maternal T cell responses. In mouse placentas, the MHC expression on labyrinthine trophoblast 


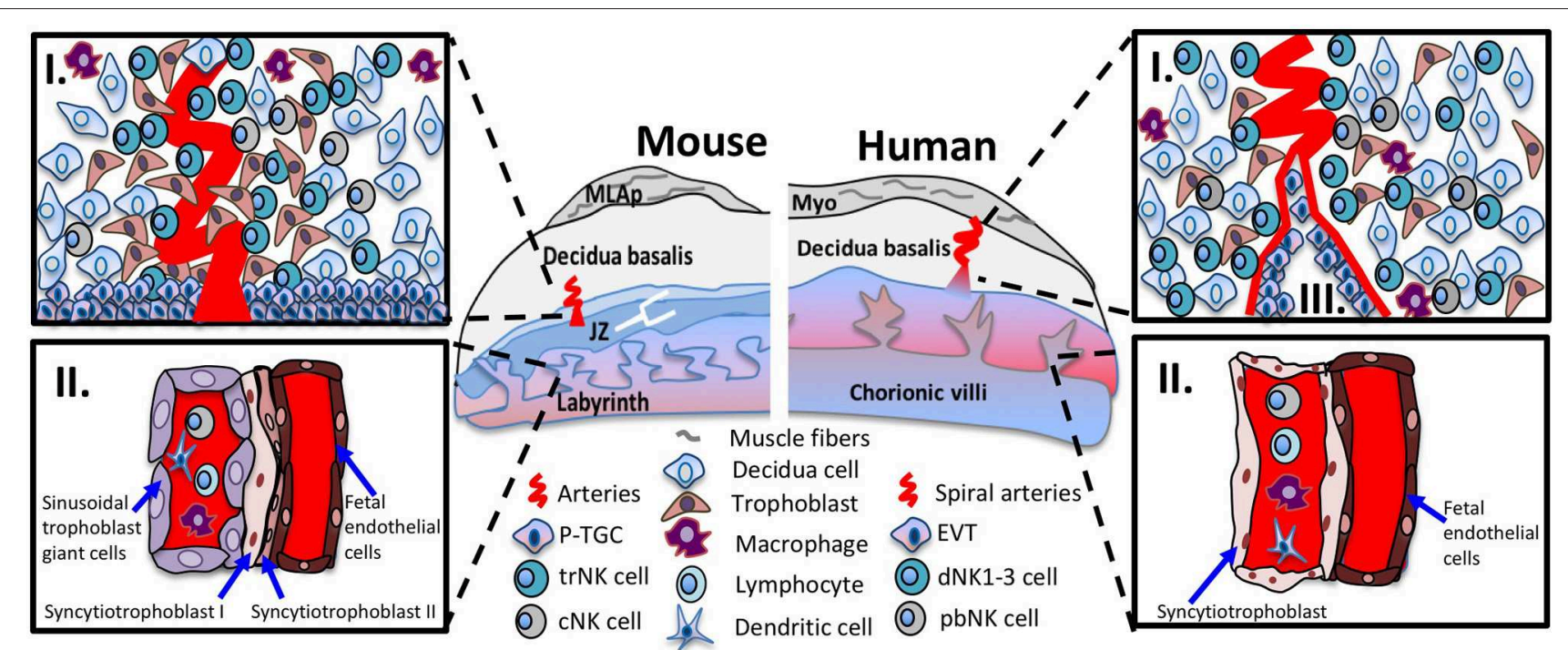

FIGURE 1 | Immunological interfaces of the mouse and human placentas. Schematic diagram of placenta positioned with maternal tissues above fetal tissues. The murine (left panel) and human (right panel) placenta. The top inset (I) shows the cellular components of midgestation decidua basalis. In mouse and human decidua basalis, NK cell subsets are in close contact with decidua cells, invading interstitial trophoblast cells and other immune cells such as macrophages and dendritic cells. The bottom inset (II) shows the interhemal membrane unit in the placental labyrinth and chorionic villi. The sinusoidal trophoblast giant cells (mouse) and syncytiotrophoblast cells (human) line the maternal blood sinus and are exposed to circulating immune cells among them, cNK cells. In human placentas, the bottom inset (III), shows the endovascular trophoblast invasion where EVTs remodel the maternal vasculature and are exposed to circulating immune cells. Abbreviations in figure: parietal trophoblast giant cells (P-TGCs), junctional zone (JZ), tissue-resident NK cell (trNK), conventional NK cell (cNK), peripheral blood (pNK) cells, decidual NK (dNK) cells, extravillous trophoblasts (EVT).

is less clear. A second immunological interface occurs in the decidualized endometrium. In a process called interstitial trophoblast invasion the EVTs in human and extra labyrinthine trophoblasts in mice are intimately positioned to interact with the maternal immune cells. For example, EVTs express the class I molecule HLA-C and non-classical class I molecules HLA-E and HLA-G. HLA-C, HLA-E, and HLA-G interact with KIR and CD94/NKG2 receptors expressed in NK cells. HLA-G binds, members of the immunoglobulin-like transcript (ILT) ILT2 and ILT4, a family of receptors expressed in NK cells to induce growth factors important for fetal development (19). Invading giant trophoblast cells (TGCs) in mouse do not express non-classical MHC-I molecules (20, 21); however, TGCs that potentially contact immune cells in the decidua basalis of the C57BL/6J B6 mice do express the classical MHC-I, H-2K (Figure 1-I). Finally, in human placentas during endovascular trophoblast invasion, the EVTs hijack and transform the maternal circulatory system to yield high capacitance, low resistance arterial flow in the placenta and interact with circulating immune cells (Figure 1-III). Hence, the different immunological interfaces, with differential expression of paternally-inherited MHC receptors, may elicit distinct maternal immune responses such as systemic responses to SynT, or local tissue-specific responses to invading trophoblasts, or both.

\section{NK CELLS IN PREGNANCY}

During pregnancy, uNK cells dominate at the implantation site in species with hemochorial placentation $(9,22-24)$. Approximately
$70 \%$ of lymphocytes at the maternal-fetal interface are uNK cells during early human and mouse gestation; this percentage declines after mid-pregnancy (25). Histologically, uNK cells are localized to human decidua basalis and mouse junctional zone and MLAp $(26,27)$. Notably, they are essentially absent from the mouse placental labyrinth (27). Here, "uNK" cells will refer to NK cells in human and mouse implantation sites. Emerging evidence indicates that uNK cells are heterogeneous and contribute to pregnancy success, although they are phenotypically and functionally distinct from conventional NK cells in the circulation (28-31).

\section{cNK Cells}

NK cells are the originating members of an assortment of innate lymphoid cells (ILCs). NK cells are a heterogeneous population in the spleen, circulating blood, and many tissues (27, 32-34). Historically, most studies investigated conventional NK (cNK) in mouse spleen and human peripheral blood. NK cells do not express antigen-specific T-cell receptors (TCRs) or B-cell receptors (BCRs), distinguishing them from the adaptive immune system $(35,36)$. Developmental studies indicate that all ILC lineages arise from common lymphoid progenitors (CLPs) (37, 38). CLPs differentiate into NK cells, ILC1s, ILC2s, ILC3s and lymphoid tissue inducer (LTi) cells $(39,40)$. The common helper ILC precursor (CHILP), the progenitor to all helper-like ILC lineages, gives rise to ILC1s, ILC2s, and ILC3s, but not LTi cells or NK cells (41). This separates cNK cell development from other ILCs and ensures that cytotoxic NK cells are distinct from ILC1s (38). 


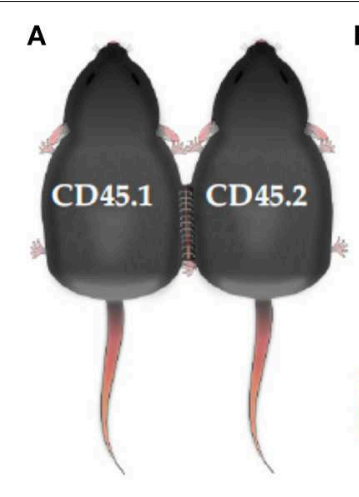

B

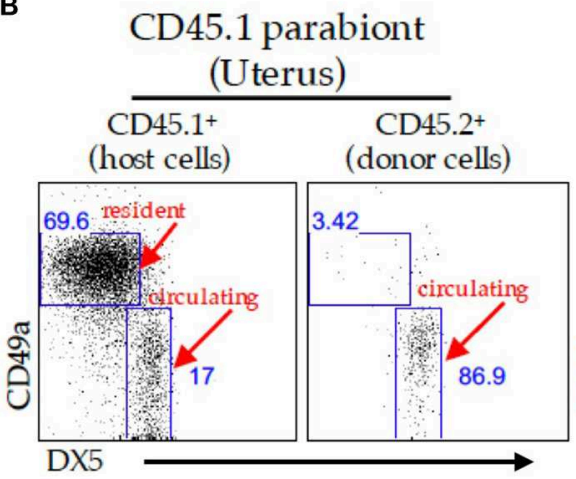

C

\section{CD45.1 parabiont} (Spleen)

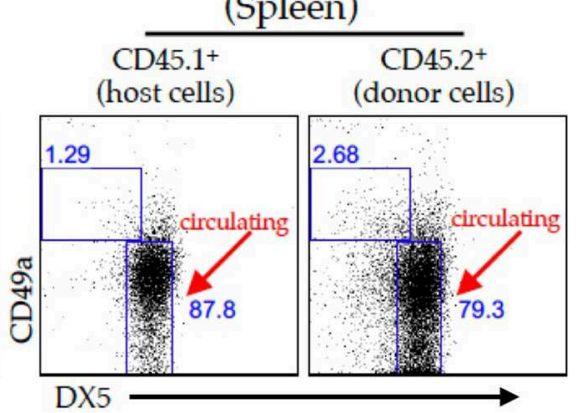

FIGURE 2 | Parabiosis model. (A) Schematic of two congenically marked animals that were surgically joined together. C57BL/6J (CD45.2) mice were parabiosed to congenic B6-Ly5.1 (CD45.1) mice. The organs were harvested on day 14 post-parabiosis surgery and analyzed using flow cytometry. A representative dot plot of the virgin uterus (B) or spleen (C) gated on live CD3- CD4- NK1.1 ${ }^{+}$cells followed by a CD45.1 gate (left panels) and CD45.2 gate (right panels) in the CD45.1 parabiont. The percentages of CD49a ${ }^{+}$and DX-5 $5^{+}$are depicted in the dot plots.

\section{trNK Cells}

We identified tissue-resident NK (trNK) cell populations in mouse liver, skin, and virgin uterus that are distinct from cNK cells (32). The trNK cells do not circulate in parabiotic mice, whereas cNK cells circulate (Figure 2). Phenotypic and RNA-seq analyses revealed that trNK and cNK cells express CD49a and DX5, respectively $(32,33)$. Liver trNK cells lack Eomesodermin (Eomes), a transcription factor expressed in cNK cells. $\mathrm{Nfil}^{-/-}$ mice have trNK cells in liver, skin, and virgin uterus, but lack cNK cells. Tbx $21^{-/-}$mice lack trNK cells in liver and skin, whereas $\mathrm{cNK}$ cell distribution is relatively unaffected at these tissues. In virgin uteri, trNK cells dominate over cNK cells and are unaffected in $\mathrm{Nfil}^{-/-}$and $\mathrm{Tb} \times 21^{-/-}$mice. Ly49 receptor expression repertoires differ between trNK and cNK cells; liver trNK cells do not express Ly49D or Ly49H. Although trNK cells have an immature phenotype, they have more diverse cytokine production than $\mathrm{cNK}$ cells. Thus, trNK and cNK cells represent divergent NK cell lineages, with a distinct trNK cell lineage in virgin uterus differing not only from cNK cell but also from liver/skin trNK cells (32).

\section{Conversion of cNK Cells}

Although trNK and cNK cells represent different lineages, recent studies suggest $\mathrm{cNK}$ cell conversion to NK cells phenotypically similar to liver ILC1 cells (42). For example, mouse CD49a ${ }^{-}$ $\mathrm{DX}^{+}$Eomes $^{+}$cNK cells can change their phenotype in a tumor microenvironment to become CD $49 \mathrm{a}^{+} \mathrm{DX}^{-}$Eomes $^{\text {int }}$, while, cNK cells convert into ILC1-like cells during Toxoplasma gondii infection (43). Human peripheral blood ( $\mathrm{pb}$ ) NK cells and hematopoietic progenitor cells isolated from decidual tissue also convert in vitro to a decidual NK cell phenotype $(44,45)$. It is currently unknown whether cNK cell conversion occurs in pregnancy.

\section{Origin of uNK Cells}

Despite differences in gestational lengths (9 months in humans vs. 19.5 days in C57BL/6J mice) and placental structure, early pregnancy consistently triggers lymphocyte accumulation within successful implantation sites $(23,46)$. Although uNK cells are ultimately derived from bone marrow $(26,47)$, studies using immunocompetent donor and alymphoid recipient mice report uNK cell accumulation during pregnancy using uterine segment transplants $(48,49)$ or adoptive splenocyte transfer $(48)$. These results indicate uterine homing of peripheral NK cells when the uterus lacked endogenous uNK cells. These findings were challenged when adoptively transferred splenic NK cells failed to home to a syngeneic, immunocompetent pregnant uterus, indicating expansion of resident progenitor NK cells (50). We recently used the parabiosis model together with experimentallyinduced decidualization to study early pregnancy events and demonstrated that trNK cells do not circulate. Rather, trNK cells proliferate locally and expand the uNK cell pool with minimal cNK cells contributions $(13,27)$. These data support a two-wave hypothesis for uNK cell accumulation during typical pregnancies $(13,27,51)$. The first wave involves local proliferation of trNK cells during decidualization; the second wave postulates the accumulation of cNK cells recruited into the decidua basalis during placentation. Whether or not trNK cells contribute to the NK cell pool of early human pregnancy remains unknown (discussed below).

\section{Human NK Cells}

In first trimester human pregnancy, NK cells represent $\sim 70 \%$ of the lymphocytes present in decidua basalis and are phenotypically and functionally distinguished from pbNK cells. Human uNK (often referred to as decidual NK cells, dNK) cells are $\mathrm{CD} 56^{\text {bright }} \mathrm{CD} 16^{-} \mathrm{KIR}^{+} \mathrm{CD} 9^{+} \mathrm{CD} 49 \mathrm{a}^{+}$while pbNK cells are $\mathrm{CD} 56^{\mathrm{dim}} \mathrm{CD} 16^{+} \mathrm{KIR}^{+}$(52). Compared to pbNK cells, uNK cells are not cytotoxic, produce lower amounts of IFN- $\gamma$ and, as in mouse, secrete VEGF that promotes angiogenesis (28, 53, 54). Single-cell RNA sequencing comparing cells isolated from first trimester decidual basalis and matched peripheral blood demonstrated three distinct NK cell subsets in decidua basalis, dNK1-3, distinct from pbNK cells (55). High dimensional 
CyTOF analysis found dNK1-3 mixed with populations of proliferating $\mathrm{dNK}, \mathrm{dILC} 3$ and pbNK cells suggestive of mixed origins of decidual lineages (31). The dNK1 cells resembled a recently identified "pregnancy trained dNK cell" subset found in repeated pregnancy (56) similarly to expanded ILC1s of mouse second pregnancy (57). Mouse models should be instrumental in clarifying the functional contributions of each uNK cell subset at the maternal-fetal interface.

\section{NK CELL FUNCTION IN PREGNANCY}

\section{Arterial Remodeling}

Understanding of how human uNK cells affect pregnancy and the placental vasculature has been challenging; however, studies of mouse uNK cells have been informative. Several mouse genetic models deficient in NK cells display aberrant modification of the uterine gestational vasculature, as their strongest reproductive phenotype. $R a g 2^{-/-} \mathrm{gc}^{-/-}$alymphoid mice, display defective spiral artery remodeling during pregnancy (58) but no defects in implantation (59). The arterial defects were rescued in bone marrow (BM) chimeric mice when $R a g 2^{-/-} g c^{-/-}$recipients received wild-type BM but not BM from interferon- $\gamma$-deficient mice. Similarly, $\mathrm{Nfil}^{-/-}$mice that lack cNK cells (32), have a smaller MLAp, aberrant uterine arterial modifications, and smaller pups $(60,61)$. Roles for interferon- $\gamma$ in dNK cellmediated vessel modification have not been confirmed in human studies. In the first trimester, uterine artery Doppler ultrasound screening can be used to identify women with poor spiral arterial remodeling predicting greater risk for preeclampsia and fetal growth restriction (62). Using in vitro analysis of EVT lines and primary explant cultures, dNK cells from the typical pregnancies promoted trophoblast motility and invasion while dNK cells from women identified as high risk for preeclampsia limited trophoblast function (63). Taken together, human and murine placental pathology supports that vascular remodeling defects are associated with preeclampsia and fetal growth restriction and linked to deficits in uNK cells numbers or functions $(64,65)$.

\section{Border Control at the Maternal-Fetal Interface}

Establishing hemochorial placentation requires aggressive invasion by trophoblast cells. Human trophoblasts show interstitial invasion, penetrating the uterine epithelium and expanding in the subjacent decidua. Rodent trophoblast invasion is significant but not as deep as human (66). Modifications of maternal blood flow are established by endovascular trophoblast invasion of implantation site decidual vessels. In humans and rats, interstitial and endovascular trophoblast invasion both extend past the decidua basalis and penetrate the inner myometrium. In mice, trophoblast invasion is interstitial and limited to the junctional zone (67). Uncontrolled trophoblast invasion that penetrates beyond the decidua into the myometrial muscle creates the life-threatening pregnancy complication called placenta accreta. A recently reported dystocia mouse model resembles human placenta accreta (60). The phenotype includes stillbirths, hemorrhage, and undelivered placentas. Histopathology revealed excessive trophoblast invasion and reduced numbers of trNK cells (68). In this model, a deficiency in the signaling adaptor molecule Grb2-associated binding protein 3 (Gab3) was important for trNK cell proliferation in response to local cytokine (IL15) stimulation. A similar outcome of dysregulated trophoblast invasion occurs in a rat model of IL15 deficient NK cells (69). These results suggest that defects in trNK cell proliferation lead to interstitial trophoblast hyperinvasion and provide insights into placenta accreta.

\section{MOUSE MODELS}

The mouse is a well-characterized genetic model system to study NK cell biology because defined mice allow reproducible experimental conditions. Discoveries in mouse NK cell biology guided subsequent studies on human NK cells. For example, Ly49A was identified as an inhibitory MHC-I-specific NK cell receptor (70) before molecular identification of $\operatorname{KIRs}(71,72)$. Liver trNK cells were identified in mouse $(32,33)$ prior to human liver trNK cell discovery (73). Endometrial sampling of ongoing human gestation is extremely limited to the narrow window for elective pregnancy termination. Sampling at delivery is more accessible, but uNK cells are rare or absent by term in both women $(74,75)$ and mice $(76)$, rendering term tissue samples inappropriate for defining normal uNK cell functions. Therefore, animal models are crucial for insights into uNK cell biology as complements to the sparse data available from human implantation sites.

\section{CONCLUSION}

Integration of data derived from experimental animal models with the limited data available from human implantation sites is essential to advance our knowledge of uNK cell biology. Despite their name, uNK cells are not good killers in pregnancy but promote placentation in response to allogeneic MHC molecules expressed on human extravillous, or mouse extralabyrinthine trophoblasts. Importantly, the maternal immune system in pregnancy does not defy the classical laws of transplantation, but actually follows these laws, in a unique and highly modified format.

\section{AUTHOR CONTRIBUTIONS}

The author confirms being the sole contributor of this work and has approved it for publication.

\section{ACKNOWLEDGMENTS}

I thank Drs. D. Michael Nelson and B. Anne Croy for critical reading and insightful comments; and Samantha Taffner for the parabiosis graphic. This review was edited by ICTS Scientific Editing Service at Washington University, supported by UL1 TR002345. 


\section{REFERENCES}

1. Brosens I, Pijnenborg R, Vercruysse L, Romero R. The "Great Obstetrical Syndromes" are associated with disorders of deep placentation. Am J Obstet Gynecol. (2011) 204:193-201. doi: 10.1016/j.ajog.2010.08.009

2. Hiby SE, Walker JJ, O'Shaughnessy KM, Redman CW, Carrington M, Trowsdale J, et al. Combinations of maternal KIR and fetal HLA-C genes influence the risk of preeclampsia and reproductive success. J Exp Med. (2004) 200:957-65. doi: 10.1084/jem.20041214

3. Hiby SE, Apps R, Sharkey AM, Farrell LE, Gardner L, Mulder A, et al. Maternal activating KIRs protect against human reproductive failure mediated by fetal HLA-C2. J Clin Invest. (2010) 120:4102-10. doi: 10.1172/JCI43998

4. Nakimuli A, Chazara O, Hiby SE, Farrell L, Tukwasibwe S, Jayaraman J, et al. A KIR B centromeric region present in Africans but not Europeans protects pregnant women from pre-eclampsia. Proc Natl Acad Sci USA. (2015) 112:845-50. doi: 10.1073/pnas.1413453112

5. Madeja Z, Yadi H, Apps R, Boulenouar S, Roper SJ, Gardner L, et al. Paternal MHC expression on mouse trophoblast affects uterine vascularization and fetal growth. Proc Natl Acad Sci USA. (2011) 108:4012-7. doi: 10.1073/pnas.1005342108

6. Kieckbusch J, Gaynor LM, Moffett A, Colucci F. MHC-dependent inhibition of uterine NK cells impedes fetal growth and decidual vascular remodelling. Nat Commun. (2014) 5:3359. doi: 10.1038/ncomms4359

7. Chaouat G, Clark DA. Are animal models useful or confusing in understanding the human feto-maternal relationship? A debate. J Reprod Immunol. (2015) 108:56-64. doi: 10.1016/j.jri.2014.10.004

8. Ander SE, Diamond MS, Coyne CB. Immune responses at the maternal-fetal interface. Sci Immunol. (2019) 4. doi: 10.1126/sciimmunol.aat6114

9. Bulmer JN, Williams PJ, Lash GE. Immune cells in the placental bed. Int J Dev Biol. (2010) 54:281-94. doi: 10.1387/ijdb.082763jb

10. Loke YW, King A, Burrows TD. Decidua in human implantation. Hum Reprod. (1995) 10(Suppl. 2):14-21. doi: 10.1093/humrep/10.suppl_2.14

11. Croy BA, Yamada AT, DeMayo FJ, Adamson SL. The Guide to Investigation of Mouse Pregnancy. Amsterdam: Academic Press (2014). p. 832.

12. Lee KY, DeMayo FJ. Animal models of implantation. Reproduction. (2004) 128:679-95. doi: 10.1530/rep.1.00340

13. Sojka DK, Yang L, Yokoyama WM. Uterine natural killer cells: To protect and to nurture. Birth Defects Res. (2018). 110:1531-38. doi: 10.1002/bdr2.1419

14. Georgiades P, Ferguson-Smith AC, Burton GJ. Comparative developmental anatomy of the murine and human definitive placentae. Placenta. (2002) 23:3-19. doi: 10.1053/plac.2001.0738

15. Barker DJP. Fetal origins of cardiovascular disease. Ann Med. (1999) 31:3-6. doi: 10.1080/07853890.1999.11904392

16. Barker DJ, Osmond C. Infant mortality, childhood nutrition, and ischaemic heart disease in England and Wales. Lancet. (1986) 1:1077-81. doi: 10.1016/S0140-6736(86)91340-1

17. Tanaka S, Kunath T, Hadjantonakis AK, Nagy A, Rossant J. Promotion of trophoblast stem cell proliferation by FGF4. Science. (1998) 282:2072-5. doi: $10.1126 /$ science.282.5396.2072

18. Coan PM, Ferguson-Smith AC, Burton GJ. Ultrastructural changes in the interhaemal membrane and junctional zone of the murine chorioallantoic placenta across gestation. J Anat. (2005) 207:783-96. doi: $10.1111 / j .1469-7580.2005 .00488 . x$

19. Fu B, Zhou Y, Ni X, Tong X, Xu X, Dong Z, et al. Natural killer cells promote fetal development through the secretion of growth-promoting factors. Immunity. (2017) 47:1100-13.e6. doi: 10.1016/j.immuni.2017.11.018

20. Moffett A, Loke C. Immunology of placentation in eutherian mammals. Nat Rev Immunol. (2006) 6:584-94. doi: 10.1038/nri1897

21. Kanbour A, Ho HN, Misra DN, MacPherson TA, Kunz HW, Gill TJ, 3rd. Differential expression of MHC class I antigens on the placenta of the rat. A mechanism for the survival of the fetal allograft. J Exp Med. (1987) 166:1861-82. doi: 10.1084/jem.166.6.1861

22. Elliot MG, Crespi BJ. Placental invasiveness mediates the evolution of hybrid inviability in mammals. Am Nat. (2006) 168:114-20. doi: 10.1086/505162

23. Stewart IJ. Granulated metrial gland cells in 'minor' species. $J$ Reprod Immunol. (1998) 40:129-46. doi: 10.1016/S0165-0378(98) 00038-2
24. Croy BA, van den Heuvel MJ, Borzychowski AM, Tayade C. Uterine natural killer cells: a specialized differentiation regulated by ovarian hormones. Immunol Rev. (2006) 214:161-85. doi: 10.1111/j.1600-065X.2006.00447.x

25. Erlebacher A. Chapter 19: Leukocyte population dynamics and functions at the maternal-fetal interface. In: Croy BA, Yamada AT, DeMayo FJ, Adamson SL, editors. The Guide to Investigation of Mouse Pregnancy. Amsterdam: Elsevier (2014). 227-42. doi: 10.1016/B978-0-12-394445-0.00019-9

26. Croy BA, He H, Esadeg S, Wei Q, McCartney D, Zhang J, et al. Uterine natural killer cells: insights into their cellular and molecular biology from mouse modelling. Reproduction. (2003) 126:149-60. doi: 10.1530/rep.0.1260149

27. Sojka DK, Yang L, Plougastel-Douglas B, Higuchi DA, Croy BA, Yokoyama WM. Cutting edge: local proliferation of uterine tissue-resident nk cells during decidualization in mice. J Immunol. (2018) 201:2551-6. doi: 10.4049/jimmunol.1800651

28. Koopman LA, Kopcow HD, Rybalov B, Boyson JE, Orange JS, Schatz F, et al. Human decidual natural killer cells are a unique NK cell subset with immunomodulatory potential. J Exp Med. (2003) 198:1201-12. doi: $10.1084 /$ jem. 20030305

29. Moffett-King A. Natural killer cells and pregnancy. Nat Rev Immunol. (2002) 2:656-63. doi: 10.1038/nri886

30. Yadi H, Burke S, Madeja Z, Hemberger M, Moffett A, Colucci F. Unique receptor repertoire in mouse uterine NK cells. J Immunol. (2008) 181:6140-7. doi: 10.4049/jimmunol.181.9.6140

31. Huhn O, Ivarsson MA, Gardner L, Hollinshead M, Stinchcombe JC, Chen $\mathrm{P}$, et al. Distinctive phenotypes and functions of innate lymphoid cells in human decidua during early pregnancy. Nat Commun. (2020) 11:381. doi: 10.1038/s41467-019-14123-z

32. Sojka DK, Plougastel-Douglas B, Yang L, Pak-Wittel MA, Artyomov MN, Ivanova $\mathrm{Y}$, et al. Tissue-resident natural killer (NK) cells are cell lineages distinct from thymic and conventional splenic NK cells. eLife. (2014) 3:e01659. doi: 10.7554/eLife.01659

33. Peng $\mathrm{H}$, Jiang $\mathrm{X}$, Chen $\mathrm{Y}$, Sojka DK, Wei H, Gao X, et al. Liver-resident NK cells confer adaptive immunity in skin-contact inflammation. J Clin Invest. (2013) 123:1444-56. doi: 10.1172/JCI66381

34. Victorino F, Sojka DK, Brodsky KS, McNamee EN, Masterson JC, Homann $\mathrm{D}$, et al. Tissue-Resident NK cells mediate ischemic kidney injury and are not depleted by anti-asialo-gm1 antibody. J Immunol. (2015) 195:4973-85. doi: 10.4049/jimmunol.1500651

35. Yokoyama WM. Chapter 17: Natural killer cells. In: Paul WE, editor. Fundamental Immunology. Philadelphia, PA: Lippincott Williams \& Wilkins (2013). p. 395-431.

36. Serafini N, Vosshenrich CA, Di Santo JP. Transcriptional regulation of innate lymphoid cell fate. Nat Rev Immunol. (2015) 15:415-28. doi: 10.1038/nri3855

37. Diefenbach A, Colonna M, Romagnani C. The ILC world revisited. Immunity. (2017) 46:327-32. doi: 10.1016/j.immuni.2017.03.008

38. Diefenbach A, Colonna M, Koyasu S. Development, differentiation, and diversity of innate lymphoid cells. Immunity. (2014) 41:354-65. doi: 10.1016/j.immuni.2014.09.005

39. Possot C, Schmutz S, Chea S, Boucontet L, Louise A, Cumano A, et al. Notch signaling is necessary for adult, but not fetal, development of RORgammat $(+)$ innate lymphoid cells. Nat Immunol. (2011) 12:949-58. doi: 10.1038/ni.2105

40. Yu X, Wang Y, Deng M, Li Y, Ruhn KA, Zhang CC, et al. The basic leucine zipper transcription factor NFIL3 directs the development of a common innate lymphoid cell precursor. Elife. (2014) 3:e04406. doi: 10.7554/eLife.04406

41. Klose CS, Flach M, Mohle L, Rogell L, Hoyler T, Ebert K, et al. Differentiation of type 1 ILCs from a common progenitor to all helper-like innate lymphoid cell lineages. Cell. (2014) 157:340-56. doi: 10.1016/j.cell.2014.03.030

42. Gao Y, Souza-Fonseca-Guimaraes F, Bald T, Ng SS, Young A, Ngiow SF, et al. Tumor immunoevasion by the conversion of effector NK cells into type 1 innate lymphoid cells. Nat Immunol. (2017) 18:1004-15. doi: 10.1038/ni.3800

43. Park E, Patel S, Wang Q, Andhey P, Zaitsev K, Porter S, et al. Toxoplasma gondii infection drives conversion of NK cells into ILC1-like cells. Elife. (2019). 8:e47605. doi: 10.7554/eLife.47605

44. Keskin DB, Allan DS, Rybalov B, Andzelm MM, Stern JN, Kopcow HD, et al. TGFbeta promotes conversion of CD16+ peripheral blood NK cells into CD16- NK cells with similarities to decidual NK cells. Proc Natl Acad Sci USA. (2007) 104:3378-83. doi: 10.1073/pnas.0611098104 
45. Vacca P, Vitale C, Montaldo E, Conte R, Cantoni C, Fulcheri E, et al. CD34+ hematopoietic precursors are present in human decidua and differentiate into natural killer cells upon interaction with stromal cells. Proc Natl Acad Sci USA. (2011) 108:2402-7. doi: 10.1073/pnas.1016257108

46. Peel S. Granulated metrial gland cells. Adv Anat Embryol Cell Biol. (1989) 115:1-112. doi: 10.1007/978-3-642-74170-8_1

47. Guimond MJ, Wang B, Croy BA. Engraftment of bone marrow from severe combined immunodeficient (SCID) mice reverses the reproductive deficits in natural killer cell-deficient tg epsilon 26 mice. J Exp Med. (1998) 187:217-23. doi: 10.1084/jem.187.2.217

48. Chantakru S, Miller C, Roach LE, Kuziel WA, Maeda N, Wang WC, et al. Contributions from self-renewal and trafficking to the uterine NK cell population of early pregnancy. J Immunol. (2002) 168:22-8. doi: 10.4049/jimmunol.168.1.22

49. Zhang JH, Yamada AT, Croy BA. DBA-lectin reactivity defines natural killer cells that have homed to mouse decidua. Placenta. (2009) 30:968-73. doi: 10.1016/j.placenta.2009.08.011

50. Chiossone L, Vacca P, Orecchia P, Croxatto D, Damonte P, Astigiano $\mathrm{S}$, et al. In vivo generation of decidual natural killer cells from resident hematopoietic progenitors. Haematologica. (2014) 99:448-57. doi: 10.3324/haematol.2013.091421

51. Sojka DK, Yang L, Yokoyama WM. Uterine natural killer cells. Front Immunol. (2019) 10:960. doi: 10.3389/fimmu.2019.00960

52. Vacca P, Pietra G, Falco M, Romeo E, Bottino C, Bellora F, et al. Analysis of natural killer cells isolated from human decidua: evidence that 2B4 (CD244) functions as an inhibitory receptor and blocks NK-cell function. Blood. (2006) 108:4078-85. doi: 10.1182/blood-2006-04-017343

53. King A, Birkby C, Loke YW. Early human decidual cells exhibit NK activity against the K562 cell line but not against first trimester trophoblast. Cell Immunol. (1989) 118:337-44. doi: 10.1016/0008-8749(89)90382-1

54. Manaster I, Mizrahi S, Goldman-Wohl D, Sela HY, Stern-Ginossar N, Lankry D, et al. Endometrial NK cells are special immature cells that await pregnancy. J Immunol. (2008) 181:1869-76. doi: 10.4049/jimmunol.181.3.1869

55. Vento-Tormo R, Efremova M, Botting RA, Turco MY, Vento-Tormo M, Meyer KB, et al. Single-cell reconstruction of the early maternal-fetal interface in humans. Nature. (2018) 563:347-53. doi: 10.1038/s41586-018-0698-6

56. Gamliel M, Goldman-Wohl D, Isaacson B, Gur C, Stein N, Yamin $\mathrm{R}$, et al. Trained memory of human uterine nk cells enhances their function in subsequent pregnancies. Immunity. (2018) 48:951-62.e5. doi: 10.1016/j.immuni.2018.03.030

57. Filipovic I, Chiossone L, Vacca P, Hamilton RS, Ingegnere T, Doisne JM, et al. Molecular definition of group 1 innate lymphoid cells in the mouse uterus. Nat Commun. (2018) 9:4492. doi: 10.1038/s41467-018-06918-3

58. Ashkar AA, Di Santo JP, Croy BA. Interferon gamma contributes to initiation of uterine vascular modification, decidual integrity, and uterine natural killer cell maturation during normal murine pregnancy. J Exp Med. (2000) 192:25970. doi: 10.1084/jem.192.2.259

59. Croy BA, Burke SD, Barrette VF, Zhang J, Hatta K, Smith GN, et al. Identification of the primary outcomes that result from deficient spiral arterial modification in pregnant mice. Pregnancy Hypertens. (2011) 1:87-94. doi: 10.1016/j.preghy.2010.10.002

60. Boulenouar S, Doisne JM, Sferruzzi-Perri A, Gaynor LM, Kieckbusch J, Balmas E, et al. The residual innate lymphoid cells in nfil3-deficient mice support suboptimal maternal adaptations to pregnancy. Front Immunol. (2016) 7:43. doi: 10.3389/fimmu.2016.00043

61. Redhead ML, Portilho NA, Felker AM, Mohammad S, Mara DL, Croy BA. The transcription factor NFIL3 is essential for normal placental and embryonic development but not for uterine natural killer (UNK) cell differentiation in mice. Biol Reprod. (2016) 94:101. doi: 10.1095/biolreprod.116.138495

62. Leslie K, Whitley GS, Herse F, Dechend R, Ashton SV, Laing K, et al. Increased apoptosis, altered oxygen signaling, and antioxidant defenses in first-trimester pregnancies with high-resistance uterine artery blood flow. Am J Pathol. (2015) 185:2731-41. doi: 10.1016/j.ajpath.2015.06.020

63. Wallace AE, Host AJ, Whitley GS, Cartwright JE. Decidual natural killer cell interactions with trophoblasts are impaired in pregnancies at increased risk of preeclampsia. Am J Pathol. (2013) 183:1853-61. doi: 10.1016/j.ajpath.2013.08.023

64. Lyall F, Robson SC, Bulmer JN. Spiral artery remodeling and trophoblast invasion in preeclampsia and fetal growth restriction: relationship to clinical outcome. Hypertension. (2013) 62:1046-54. doi: 10.1161/HYPERTENSIONAHA.113.01892

65. Burke SD, Karumanchi SA. Spiral artery remodeling in preeclampsia revisited. Hypertension. (2013) 62:1013-4. doi: 10.1161/HYPERTENSIONAHA.113.02049

66. Redline RW, Lu CY. Localization of fetal major histocompatibility complex antigens and maternal leukocytes in murine placenta. Implications for maternal-fetal immunological relationship. Lab Invest. (1989) 61:27-36.

67. Ain R, Canham LN, Soares MJ. Gestation stage-dependent intrauterine trophoblast cell invasion in the rat and mouse: novel endocrine phenotype and regulation. Dev Biol. (2003) 260:176-90. doi: 10.1016/S0012-1606(03)00210-0

68. Sliz A, Locker KCS, Lampe K, Godarova A, Plas DR, Janssen EM, et al. Gab3 is required for IL-2- and IL-15-induced NK cell expansion and limits trophoblast invasion during pregnancy. Sci Immunol. (2019) 4:eaav3866. doi: 10.1126/sciimmunol.aav3866

69. Renaud SJ, Scott RL, Chakraborty D, Rumi MA, Soares MJ. Natural killer-cell deficiency alters placental development in rats. Biol Reprod. (2017) 96:145-58. doi: 10.1095/biolreprod.116.142752

70. Karlhofer FM, Ribaudo RK, Yokoyama WM. MHC class I alloantigen specificity of Ly-49+ IL-2-activated natural killer cells. Nature. (1992) 358:6670. doi: $10.1038 / 358066 \mathrm{a} 0$

71. Wagtmann N, Biassoni R, Cantoni C, Verdiani S, Malnati MS, Vitale M, et al. Molecular clones of the p58 NK cell receptor reveal immunoglobulinrelated molecules with diversity in both the extra- and intracellular domains. Immunity. (1995) 2:439-49. doi: 10.1016/1074-7613(95)90025-X

72. Colonna M, Samaridis J. Cloning of immunoglobulin-superfamily members associated with HLA-C and HLA-B recognition by human natural killer cells. Science. (1995) 268:405-8. doi: 10.1126/science.7716543

73. Aw Yeang HX, Piersma SJ, Lin Y, Yang L, Malkova ON, Miner C, et al. Cutting Edge: Human CD49e- NK cells are tissue resident in the liver. J Immunol. (2017) 198:1417-22. doi: 10.4049/jimmunol. 1601818

74. King A. Uterine leukocytes and decidualization. Hum Reprod Update. (2000) 6:28-36. doi: 10.1093/humupd/6.1.28

75. Williams PJ, Searle RF, Robson SC, Innes BA, Bulmer JN. Decidual leucocyte populations in early to late gestation normal human pregnancy. J Reprod Immunol. (2009) 82:24-31. doi: 10.1016/j.jri.2009. 08.001

76. Delgado SR, McBey BA, Yamashiro S, Fujita J, Kiso Y, Croy BA. Accounting for the peripartum loss of granulated metrial gland cells, a natural killer cell population, from the pregnant mouse uterus. J Leukoc Biol. (1996) 59:262-9. doi: $10.1002 /$ jlb.59.2.262

Conflict of Interest: The author declares that the research was conducted in the absence of any commercial or financial relationships that could be construed as a potential conflict of interest.

Copyright (c) 2020 Sojka. This is an open-access article distributed under the terms of the Creative Commons Attribution License (CC BY). The use, distribution or reproduction in other forums is permitted, provided the original author(s) and the copyright owner(s) are credited and that the original publication in this journal is cited, in accordance with accepted academic practice. No use, distribution or reproduction is permitted which does not comply with these terms. 